\title{
Effects of short-time exposure to atrazine on miRNA expression profiles in the gonad of common carp (Cyprinus carpio)
}

\author{
Fang Wang, Qian-wen Yang, Wen-Jie Zhao, Qi-Yan Du and Zhong-Jie Chang*
}

\begin{abstract}
Background: Atrazine is widely used in agriculture and is a known endocrine disrupting chemical. Atrazine can seep into the water body through surface, posing a potential threat to the aquatic ecological environment and human drinking water source. In vertebrate, studies have shown that it can affect reproduction and development seriously, but its molecular mechanism for aquatic animals is unknown. Aquaculture is very common in China, especially common carp, whose females grow faster than males. However, the effects of atrazine on the reproduction of carp, especially miRNA, have not been investigated.
\end{abstract}

Results: In this study, common carp (Cyprinus carpio) at two key developmental stages were exposed to atrazine in vitro. Sex ratio was observed to analyze the effect of atrazine on the sex. MiRNA expression profiles were analysed to identify miRNAs related to gonad development and to reveal the atrazine mechanisms interfering with gonad differentiation. The results showed that the sex ratio was biased towards females. Atrazine exposure caused significant alteration of multiple miRNAs. Predicted targets of differently-expressed miRNAs were involved in many reproductive biology signalling pathways.

Conclusions: Our results indicate that atrazine promoted the expression of female-biased genes by decreasing miRNAs in primordial gonad. In addition, our results indicate that atrazine can up-regulate aromatase expression through miRNAs, which supports the hypothesis that atrazine has endocrine-disrupting activity by altering the gene expression profile of the Hypothalamus-Pituitary-Gonad axis through its corresponding miRNAs.

Keywords: Atrazine, Targeting analysis, MicroRNA, Gonad development, Cyprinus carpio

\section{Background}

Sex determination in fish is significantly influenced by environmental factors, such as temperature, $\mathrm{pH}$, exogenous hormones, and pollutants [1]. Pollutants, such as pesticides, are potential endocrine disruptors, which even at very low levels are sufficient to cause developmental and reproductive alterations in numerous species [2,3].

With the development of agriculture, herbicides are increasingly used to avoid the manual removal of weeds, to reduce soil erosion, and to increase crop production rates [4]. However, the use of pesticides leads to serious harm to living organisms. Atrazine is a pre-emergent herbicide which is widely used on a variety of agricultural crops

\footnotetext{
* Correspondence: 041004@htu.edu.cn

College of Life Science, Henan Normal University, Xinxiang, Henan 453007, People's Republic of China
}

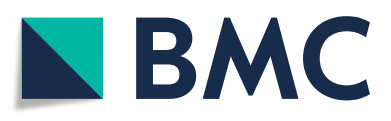

(c) The Author(s). 2019 Open Access This article is distributed under the terms of the Creative Commons Attribution 4.0 International License (http://creativecommons.org/licenses/by/4.0/), which permits unrestricted use, distribution, and reproduction in any medium, provided you give appropriate credit to the original author(s) and the source, provide a link to the Creative Commons license, and indicate if changes were made. The Creative Commons Public Domain Dedication waiver (http://creativecommons.org/publicdomain/zero/1.0/) applies to the data made available in this article, unless otherwise stated.

including sorghum grass, corn, wheat, and sugar cane, is frequently contaminating potable water supplies [5-8]. Atrazine alters male reproductive tissues when animals are exposed to during development, which makes it a suspected endocrine-disrupting chemical.

Various studies indicate that atrazine may act as a potential carcinogen, which adversely affects the neuroendocrine and reproductive systems [9-12]. Currently, the epigenetic, genetic, and cellular mechanisms altered by atrazine exposure are being studied [13-18]. Study in African clawed frogs (Xenopus laevis) showed that atrazine exposure, for as little as $48 \mathrm{~h}$ at $21 \mathrm{ppb}$, resulted in severe gonad dysgenesis [19]. Moreover, atrazine can induce hermaphroditism at concentrations of only $0.1 \mathrm{ppb}$ [20]. In fish, exposure to atrazine can result in all-female sex ratio in zebrafish (Danio rerio) [21]. 
In zebrafish, atrazine exposure during embryonic development alters miRNAs, which play important roles in angiogenesis, cancer, and neurodevelopment [22]. Numerous studies have shown that atrazine has adverse effects on the neuroendocrine system, primarily affecting the hypothalamus-pituitary-gonad (HPG) axis. Atrazine decreases gonadotropin-releasing hormone release, the pre-ovulatory surge of luteinizing hormone, follicle stimulating hormone, and prolactin [17, 23-26]. However, the mechanism of action of atrazine is not well-understood.

MiRNAs is a class of single-stranded, highly conserved, non-coding RNA molecules of 19-24 nucleotides (nt), which regulate gene expression at the posttranscriptional level, by targeting specific sites in the 3' untranslated region of mRNAs [27-29]. miRNAs play important roles in controlling multiple biological processes, such as cell proliferation and differentiation, embryonic development, apoptosis, cell cycle control, and immune and stress responses in various organs [30-34]. In the last few years, miRNAs have been reported to play an important role in the response to toxicant exposure and in the process of toxicant-induced tumorigenesis [35-37].

As a new tool for risk assessment, miRNAs can provide indications on the toxicology mechanisms associated with environmental factors and with disease. MiRNAs are also novel biomarkers of the diseases related to environmental factors [38]. Recently, an increasing number of studies have shown that miRNAs can functionally interact with a variety of environmental factors, such as drugs, viruses, radiation, and environmental chemicals [39-41]. Knowledge on the role miRNAs in toxicological responses is increasing, but is still limited.

As one of the most important cyprinid species, common carp, Cyprinus carpio, is widely cultivated [42]. Great progress has been made in the study of carp genomic recently. Common carp transcriptome was deep sequenced by Ji et al. (2012) and Jiang et al. (2016) [43, 44], who identified changes at the transcriptomic level in common carp spleen after $24 \mathrm{~h}$ of experimental infection with Aeromonas hydrophila. Using next generation sequencing, a large number of gene associated singlenucleotide polymorphisms (SNPs) as well as miRNA and miRNA-related SNPs were identified in four strains of common carp [45]. Studies also showed that miRNArelated SNPs can affect biogenesis and regulation in the common carp [46].

Yellow River carp is commercially important species in China, famous for its tender, tasty, and nutritional meat. Females grow faster than males, which makes the mechanism of sex differentiation and development an intriguing topic in this species [47, 48]. In our previous study, we profiled miRNAs from five different developmental stages of Yellow River carp, in order to identify differentially-expressed and novel miRNAs that may play important regulatory roles in ovary differentiation [49]. Our previous study showed that there is a dynamic shift in gene expression during gonad differentiation and development [50]. Environmental factors can affect miRNAs in fish, and even play a decisive role in some species.

Several studies have shown that in zebrafish and human atrazine exposure alters miRNAs associated with angiogenesis, cancer, and neurological development [51]. However, few studies have demonstrated the role of miRNAs in toxicological responses during sex differentiation and development in teleost fish.

In this study, we looked for correlations of miRNA and mRNA expressions during sex differentiation and development of carp, following atrazine exposure. The gonad development of carp has several critical periods, including primordial gonad and juvenile gonad. It would be valuable to understand the gene expression changes and the roles of miRNAs during the key stages of gonad development of carp, when they are exposed to atrazine. Therefore we aimed to investigate the effect of atrazine exposure on the global expression profile of miRNAs in the two key stages of gonad development by deep sequencing. We also predicted target genes that would affect gonad development. Our results would help us to better understand the molecular mechanisms of atrazine toxicity on gonad development, and to reveal the roles of miRNA-mRNA interactions in toxicological mechanisms, and the important impact on sex differentiation and gonad development of common carp.

\section{Results}

\section{Effect of exposure to different concentration of atrazine} on sex ratio

The gonads of carp were examined under a dissecting microscope to evaluate the sex at $130 \mathrm{dph}$. The results indicated that the effect of exposure to different concentration of atrazine on sex ratio in Yellow river carp were remarkable. The female percentage increased with increase of atrazine. When the concentration of atrazine in aquatic water was $0,4.28,42.8$, or $428 \mu \mathrm{g} / \mathrm{L}$, the female percentage were $48,54,61$ and $72 \%$ respectively (Fig. 1).

\section{Construction of CDNA libraries for sequencing and small- RNA discovery}

Nine cDNA libraries of small RNAs were constructed using pooled total RNAs from gonad tissues exposed to atrazine or control tissues collected from primordial gonad (PG) and from juvenile gonad stage carps. After filtering out low quality sequences, $5^{\prime}$ and 3 ' adapters, and reads < $18 \mathrm{nt}$, A total of 10,281,292, 10,086,295, $11,985,647,10,080,133,11,724,632,11,604,659,11,502$, $749,11,030,073$, and $11,282,882$ clean reads were obtained from the nine libraries. Solexa sequencing was 


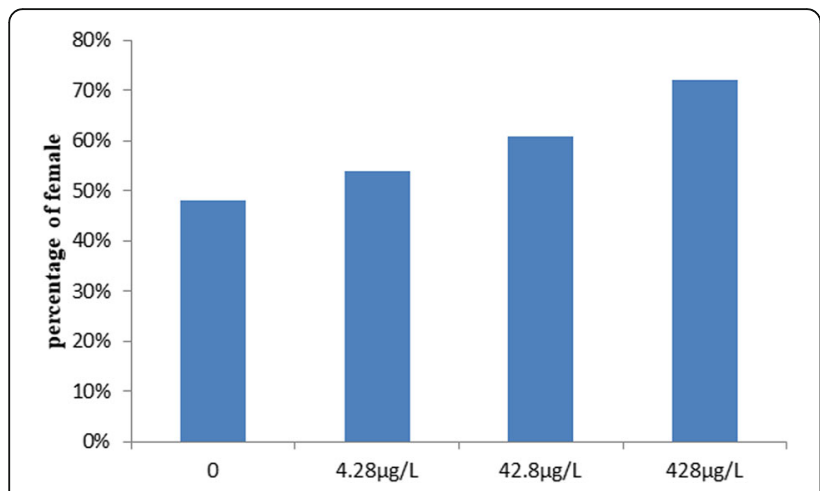

Fig. 1 Percentage of female after exposed to different concentrations of atrazine

then performed for further analysis (Table 1). we removed known types of RNA sequences including rRNA (3.84, 8.80, 8.84, 41.84, 16.31, 5.34, 0.85, 4.42 and 50.12\%, respectively), tRNA $(2.16 \% ; 1.84 \% ; 1.08 \% ; 0.47 \% ; 1.08 \% ; 2.72 \% ; 0.58 \%$; 2.79\%; and 0.37\%), small nuclear RNA (snRNA), small nucleolar RNA (snoRNA), and repeat sequences after comparing the small-RNA sequences with NCBI GenBank and RFam. The clean reads of small RNAs from the nine libraries were mapped to the common carp genome with miRDeep2 software. A total of 4,895,831 (82.84\%); 4,657,428 (84.16\%); 7,083,013(84.91\%); 5,536,128 (90.12\%); 6,104,227 (86.69\%); 5,627,337 (82.83\%); 5,334,147 (79.12\%); 5,337,365 (79.15\%) and 7,463,759 (89.37\%) of miRNA clean reads were mapped to the genome. The length distribution of the highquality reads had different trends in the samples within the nine libraries. In the case of PG-CK samples, two peaks of length were observed at $22 \mathrm{nt}$ and $27 \mathrm{nt}$. However, the size distribution of 21-23 nt increased and the size distribution of 26-29 nt decreased, after exposed to atrazine for $8 \mathrm{~h}$ and $24 \mathrm{~h}$ (Fig. 2). In the case of IIX-CK samples, higher miRNA mapped rates were observed in small RNAs of 26-28 nt in length. The size distribution of 21-23 nt increased and the size distribution of 26-29 nt decreased after exposure to atrazine for $8 \mathrm{~h}$ and $24 \mathrm{~h}$ (Fig. 2). In the case of IIC-CK samples, higher miRNA mapped rates were observed in small RNAs of 21-23 nt in length. The size distribution of 21-23 nt decreased and the size distribution of 27-29 nt increased after exposure to atrazine for $8 \mathrm{~h}$ and $24 \mathrm{~h}$ (Fig. 2). Small RNAs with length of 26-29 nt corresponded to Piwiinteracting RNAs (piRNAs) (Fig. 2), which are endogenous small non-coding RNA molecules $26-31 \mathrm{nt}$ in length. Various studies have shown that Piwi-piRNA complexes have essential roles in gene silencing and in transposon regulation during germ cell differentiation and gonad development in animals [52-54].

\section{Identification of miRNAs}

To identify miRNAs in the gonad of the Yellow River carp exposed or not to atrazine, the clean reads were used and the miRNAs identified by comparison to the deposited miRNAs from miRBase. Mireap_v0.2 software was used for secondary structure prediction of novel miRNA. There was a total of 4443 miRNAs that were identified, including 3795 existing miRNAs, and 648 conserved miRNAs. Among the existing and conserved miRNAs, 7 miRNAs (ccr-miR-26a, ccr-miR-10b, ccr-miR143, ccr-miR-181a, ccr-miR-100, ccr-miR-22a, and ccrmiR-92a) were the most abundant $(\mathrm{TPM}>10,000)$ in all samples $(\mathrm{TPM}=$ Readout $\times 1,000,000 /$ Mapped reads).

Table 1 Distribution of sequenced clean reads

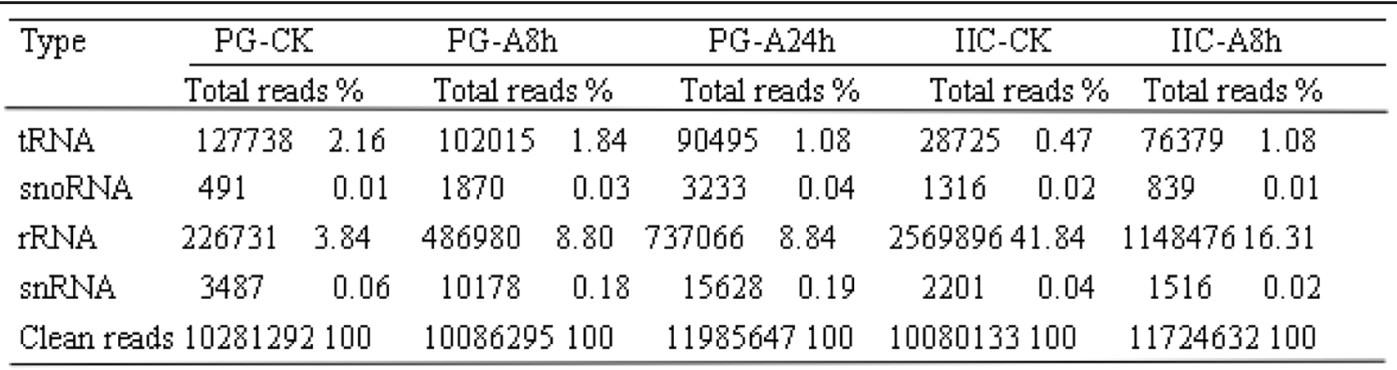

\begin{tabular}{lllllllll}
\hline \multirow{2}{*}{ Type } & \multicolumn{2}{c}{ IIC-A24h } & \multicolumn{2}{c}{ IIX-CK } & \multicolumn{2}{c}{ IIX-A8h } & \multicolumn{2}{l}{ ILX-A24h } \\
\cline { 2 - 9 } & \multicolumn{2}{c}{ Total reads $\%$} & \multicolumn{2}{c}{ Total reads $\%$} & \multicolumn{2}{c}{ Total reads $\%$} & \multicolumn{2}{l}{ Total reads \% } \\
\hline tRNA & 184690 & 2.72 & 38943 & 0.58 & 188272 & 2.79 & 30837 & 0.37 \\
snoRNA & 206 & 0.00 & 161 & 0.00 & 3072 & 0.05 & 8262 & 0.10 \\
fRNA & 362576 & 5.34 & 57360 & 0.85 & 297759 & 4.42 & 4185775 & 50.12 \\
snRNA & 4984 & 0.07 & 611 & 0.01 & 10599 & 0.16 & 32132 & 0.38 \\
Clean reads & 11604659 & 100 & 11502749 & 100 & 11030073 & 100 & 11282882 & 100 \\
\hline
\end{tabular}



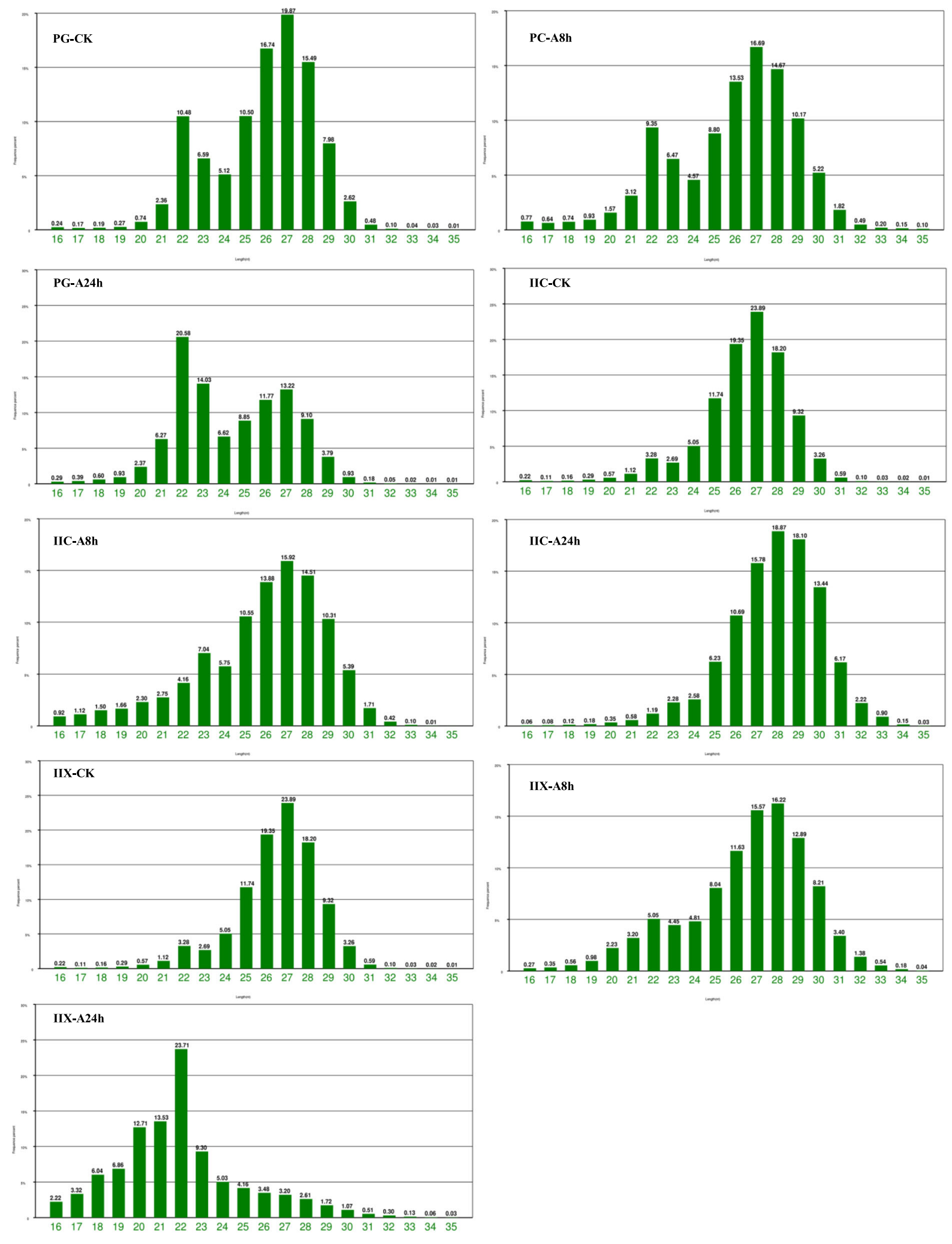

Fig. 2 (See legend on next page.) 
(See figure on previous page.)

Fig. 2 Length distribution of miRNA sequences from Yellow River carp in primordial gonad control (PG-CK), primordial gonad exposed to atrazine for $8 \mathrm{~h}$ (PG-A8h), primordial gonad exposed to atrazine for $24 \mathrm{~h}$ (PG-A24h), juvenile ovary control (IIC-CK), juvenile ovary exposed to atrazine for 8 h (IIC-A8h), juvenile ovary exposed to atrazine for $24 \mathrm{~h}$ (IIC-A24h), juvenile testis control (IIX-CK), juvenile testis exposed to atrazine for $8 \mathrm{~h}$ (IIX-A8h), juvenile testis exposed to atrazine for $24 \mathrm{~h}$ (IIX-A24h)

\section{Validation of miRNAs with qPCR}

To validate the results of Solexa sequencing, qPCR was used to test six randomly-selected (ccr-miR-24, ccr-miR146a, ccr-miR-192, ccr-miR-21, ccr-miR-143, and ccrmiR-454b) miRNAs. According to sequence analysis, from the miRNAs selected for comparison, three miRNAs (ccr-miR-146a, ccr-miR-21, and ccr-miR-454b) were upregulated in juvenile ovary gonad at $24 \mathrm{~h}$ whereas three miRNAs (ccr-miR-24, ccr-miR-192, and ccr-miR-143) were down-regulated in juvenile ovary at $24 \mathrm{~h}$ of atrazine exposure. The relative expression levels of all six miRNAs were consistent with the sequencing data (Fig. 3), indicating the reliability of the miRNA expression and correlation analysis.

\section{Effects of atrazine exposure on miRNA expression in PG of Yellow River carp}

Primordial gonad is a critical period of sex differentiation, because of the formation of primordial germ cell. A comparative analysis of miRNA expression profiles with or without atrazine exposure may reveal miRNAs with important roles in early gonad differentiation. The results showed that atrazine exposure resulted in the altered expression of a larger number of miRNAs in PG compared with control. Atrazine exposure not only affected the total number of detectable miRNAs, but also the expression levels of miRNAs. After atrazine exposure for $8 \mathrm{~h}$ and $24 \mathrm{~h}$, we observed different patterns of differentially-expressed miRNAs in PG of carp. Compared with the control group, 277 miRNAs were increased and 334 miRNAs were decreased after atrazine exposure for $8 \mathrm{~h}$. A significant difference in miRNA expression was observed between samples from atrazine exposure for $24 \mathrm{~h}$ and unexposed controls, $181 \mathrm{miRNAs}$ were increased and 1056 miRNAs were decreased (Fig. 4) . The most significantly down-regulated miRNAs were miR-205, miR-184 and miR-203b-3p, which were downregulated by $7.15,3.61$ and 3.35 fold, respectively. The most significantly up-regulated miRNAs were miR-7132, miR-135c, and miR-187 which were up-regulated by 8.70, 2.88 and 2.48 fold, respectively (Table 2). Atrazine exposure for $24 \mathrm{~h}$ had a greater effect on carp PG miRNA expression than the exposure for $8 \mathrm{~h}$. The number of miRNAs with altered expression after atrazine exposure was higher at $24 \mathrm{~h}$ than at $8 \mathrm{~h}$. However, the extent of change varied among the miRNAs. For example, the expression levels of miR-135c and miR-738 increased significantly (2.21- and 2.47-fold, respectively), whereas the expression levels of miR-203a decreased significantly (12.0-fold). Similarly, the changes in miRNA expression in PG varied between the unexposed control and atrazine exposure for $8 \mathrm{~h}$ or $24 \mathrm{~h}$. For example, miR-135c was up-regulated by 2.2 -fold after atrazine exposure for $8 \mathrm{~h}$ and was up-regulated by 2.8 -fold after atrazine exposure for 24h. MiR-122 was upregulated by 1.4-fold after atrazine exposure for $8 \mathrm{~h}$, but was down-regulated by 2.9-fold after atrazine exposure for $24 \mathrm{~h}$. The miRNAs that were significantly altered in PG after exposure to atrazine may thus be involved in sex differentiation and development, and their importance in sex differentiation mechanisms needs to be clarified.

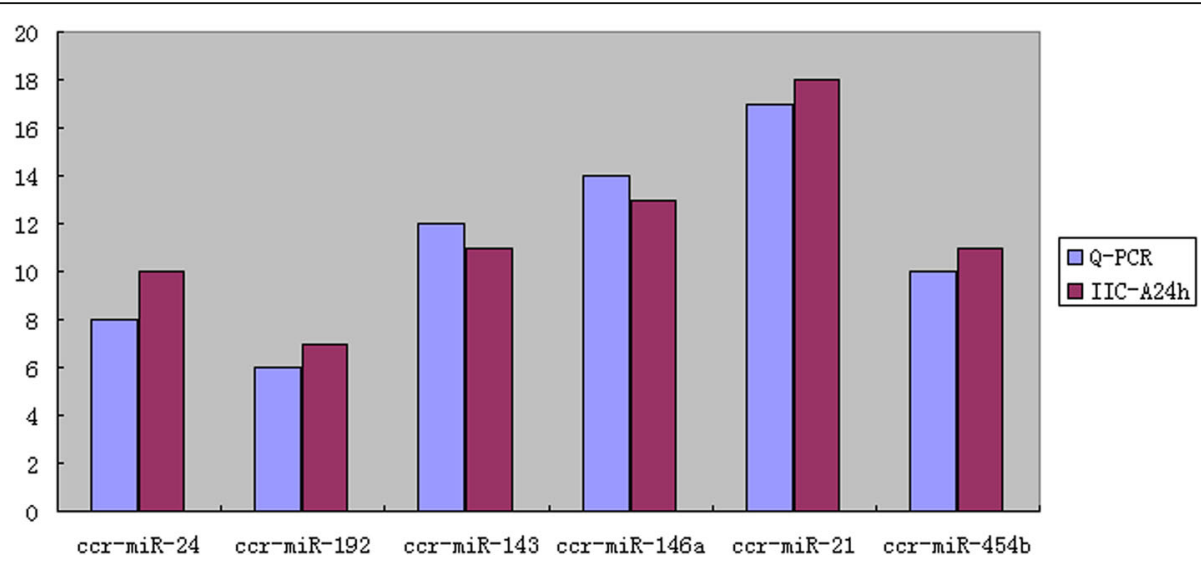

Fig. 3 Real-time quantitative PCR gene expression analysis of six randomly-selected miRNAs. Gene expression was normalized to the level of U6 SnRNA 


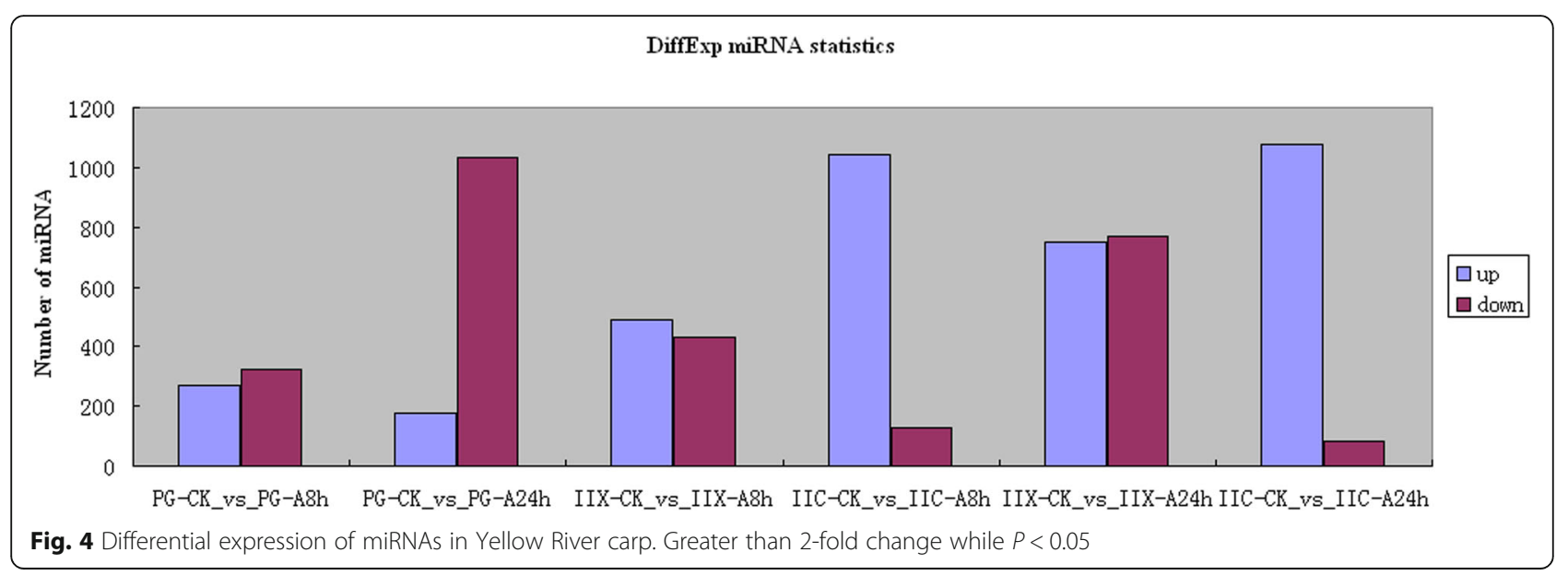

\section{Effects of atrazine exposure on miRNA expression in juvenile gonad of Yellow River carp}

We observed patterns of differentially-expressed miRNAs in juvenile gonad (stage II ovary and stage II testis) of carp after atrazine exposure for $8 \mathrm{~h}$ and $24 \mathrm{~h}$, especially in juvenile ovary (Fig. 4). In juvenile ovary, 1053 miRNAs were increased and 132 miRNAs were decreased after atrazine exposure for $8 \mathrm{~h}$, relative to unexposed controls. Relative to the control group, 1085 miRNAs were increased and 84 miRNAs were decreased after atrazine exposure for $24 \mathrm{~h}$. The most significantly decreased miRNAs were miR-184, miR-214 and miR-122, which were decreased by $13.69,13.21$ and 12.40 fold respectively. The most significantly increased miRNAs were miR-17-3p, miR-454a, and miR-454b which were increased by $2.95,2.49$ and 2.42 fold respectively. In juvenile testis, 561 miRNAs were increased and 434 miRNAs were decreased after atrazine exposure for $8 \mathrm{~h}$, relative to the control group. Compared with the control group, 775 miRNAs were increased and 799 miRNAs were decreased after atrazine exposure for $24 \mathrm{~h}$. The most significantly down-regulated miRNAs were miR-205, miR-194, and miR-122, which were decreased by $14.27,13.59$, and 11.81 fold, respectively. The most significantly up-regulated miRNAs were miR-489, miR-738, and miR-193a, which were up-regulated by $10.61,4.53$, and 2.50 fold, respectively. Atrazine exposure for $24 \mathrm{~h}$ had a greater effect on juvenile testis miRNA expression than $8 \mathrm{~h}$ exposure. In addition, atrazine treatment led to a larger number of miRNAs with altered expression in juvenile testis, than in juvenile ovary. The number of down-regulated miRNAs was higher in juvenile testis than in ovary which is consistent with the feminizing effects of atrazine.

The extent of expression change varied among miRNAs. For example, in juvenile ovary, expression levels of miR-301a and miR-17-3p decreased by 1.38- and 2.95-fold after atrazine exposure for $24 \mathrm{~h}$, respectively. In contrast, the miR-101b expression level decreased by 1.01 -fold. In juvenile testis, expression levels of miR-193a and miR-146a increased by 2.50 - and 1.71-fold, respectively, after atrazine

Table 2 miRNAs with significant expression alterations after atrazine exposure in Yellow River Carp

\begin{tabular}{|c|c|c|c|}
\hline Name & Sample & $\mathrm{U}_{\mathrm{p}}$ or Down & $\log 2(\mathrm{FC})$ \\
\hline ccr-let-7a & PG-A24h & down-regulation & -1.36 \\
\hline ccr-miR-135c & PG-A24h & up-regulation & 2.88 \\
\hline ccr-miR-122 & PG-A8h & up-regulation & 1.48 \\
\hline ccr-miR-192 & ПC-A8h & down-regulation & -3.13 \\
\hline $\mathrm{ccr}-\mathrm{miR}-146 \mathrm{a}$ & IC-A24h & up-regulation & 2.13 \\
\hline ccr-miR-184 & IC-A24h & down-regulation & -13.70 \\
\hline ccr-let-7b & एХ-A8h & up-regulation & 1.17 \\
\hline ccr-miR-101a & $\Pi \mathrm{X}-\mathrm{A} 24 \mathrm{~h}$ & down-regulation & -1.34 \\
\hline ccr-miR-205 & $\mathbb{} \mathbb{X}-\mathrm{A} 24 \mathrm{~h}$ & down-regulation & -14.27 \\
\hline ccr-miR-193a & $\mathbb{Z X}-\mathrm{A} 24 \mathrm{~h}$ & up-regulation & 2.51 \\
\hline
\end{tabular}


exposure for with $24 \mathrm{~h}$. In contrast, the expression levels of miR-122 decreased by 11.81-fold. Similarly, the changes in miRNA expression of juvenile ovary and testis varied between unexposed controls and atrazine exposure for $8 \mathrm{~h}$ or $24 \mathrm{~h}$. For example, ccr-miR-210 was down-regulated by 1.36-fold after atrazine exposure for $8 \mathrm{~h}$, and was downregulated by 2.06 -fold after atrazine exposure for $24 \mathrm{~h}$ in juvenile ovary. Ccr-miR-192 was down-regulated by 3.12fold after atrazine exposure for $8 \mathrm{~h}$, and was downregulated by 4.07 -fold after atrazine exposure for $24 \mathrm{~h}$ (Table 2). In juvenile testis, ccr-miR-205 was downregulated by 3.50 -fold after atrazine exposure for $8 \mathrm{~h}$ but was down-regulated by 14.27 -fold after atrazine exposure for $24 \mathrm{~h}$ (Table 2). The miRNAs that were significantly altered in juvenile gonad after exposure to atrazine may thus be involved in sex differentiation and development, and their importance in sex differentiation mechanisms needs to be clarified.

\section{Expression patterns of miRNAs at different gonad developmental stages in Yellow River carp}

Trend analysis of miRNA expression after exposure to atrazine for $8 \mathrm{~h}$ and $24 \mathrm{~h}$, at different developmental stages, was conducted. In PG, we identified eight different expression patterns (Fig. 5), including 25 miRNAs that were up-regulated and 214 that were down-regulated during atrazine exposure (Fig. 5, profiles 3, 0). Expression of 232 miRNAs, such as miR-1 and miR-133a-3p, increased after exposure for $8 \mathrm{~h}$, but decreased at $24 \mathrm{~h}$ (Fig. 5, profile 5). In contrast, 129 miRNAs, including miR-29a and miR-29b, showed the opposite expression pattern during atrazine exposure (Fig. 5, profile 2). In juvenile ovary, 8 different expression patterns (Fig. 5) were identified, including 440 miRNAs that were increased and 26 that were decreased during atrazine exposure (Fig. 5, profiles 7, 0). Expression of 157 miRNAs, such as mir-202-y and mir-27c-5p, increased after exposed for $8 \mathrm{~h}$, but decreased at $24 \mathrm{~h}$ (Fig. 5, profile 5). In contrast, 70 miRNAs, including miR-155 and miR-92b, showed the opposite expression pattern during atrazine exposure (Fig. 5, profile 2). In juvenile testis, we also identified eight different expression patterns (Fig. 5), including 68 miRNAs that were up-regulated and 73 that were down-regulated during exposure (Fig. 5, profiles 7, 0). Expression of 117 miRNAs, such as mir-15a and mir-16a, increased after atrazine exposure for $8 \mathrm{~h}$, but decreased at $24 \mathrm{~h}$ (Fig. 5, profile 5). In contrast, 41 miRNAs, including miR-144 and miR-148, showed the opposite expression pattern during atrazine exposure (Fig. 5, profile 2).

In this study, miRNAs targeting male-biased genes showed an upward trend. In PG, miR-499, which was predicted to target sox9, increased after exposure to atrazine (Fig. 5, profile 7). Gsdf which was targeted by miR-146a and of miR-22a, also increased after exposure to atrazine (Fig. 5 profile 7). The expression patterns of miR-72-x and miR-212-y, which were predicted to target $d m r t$, were also consistent with the above miRNAs which predicted male-biased target genes (Fig. 5, profile 7). In juvenile ovary, novel-m3245-5p, which was predicted to target sox 9 , increased after exposure to atrazine (Fig. 5, profile 7). Gsdf which was targeted by novel-m0192-3p and novel-m0514-3p, also increased after exposure to atrazine (Fig. 5, profile 7). MiR-454a and miR-454b, which were predicted to target atm, increased after exposure to atrazine (Fig. 5, profile 7). The expression patterns of novel-m0515-3p and novelm0080-5p, which were predicted to target $d m r t$, were consistent with the above miRNAs which predicted male-biased target genes (Fig. 5, profile 18). In juvenile testis, novel-m3312-3p, which is predicted to target sox 9 , increased after exposure to atrazine (Fig. 5, profile 7). Atm, which was the predicted target of novel-m0167-3p and novel-m0417-3p, also increased after exposure to atrazine (Fig. 5, profile 7).

In contrast, miRNAs targeting female-biased genes showed a downward trend. Expression levels of novel$\mathrm{m} 0101-3 \mathrm{p}$ and novel-m3450-3p in PG, miR-101b in juvenile ovary, and miR-203b-3p in juvenile testis, all of

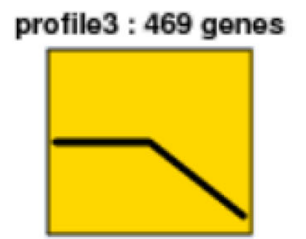

profile2 : 129 genes

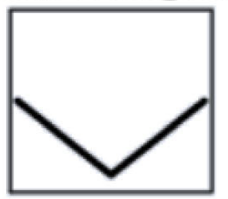

profile $1: 377$ genes

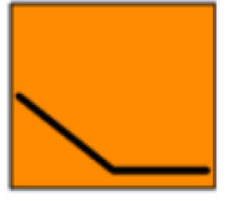

profile4 : 54 genes

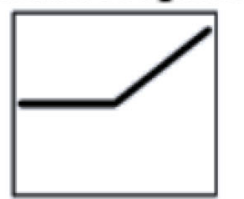

profile $5: 232$ genes profile $0: 214$ genes

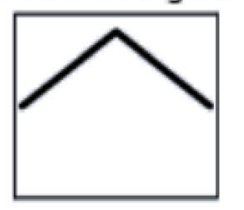

profile $7: 25$ genes profile 6 : 178 genes
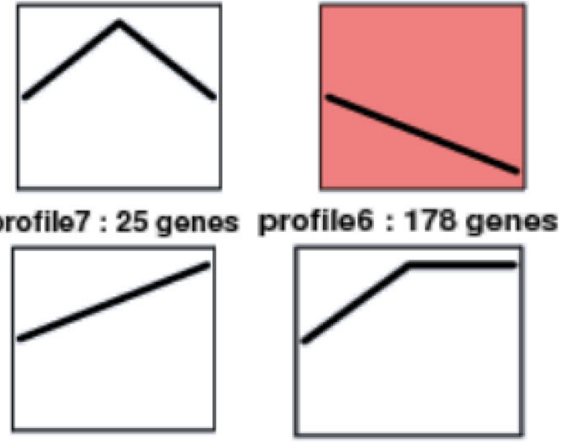

Fig. 5 Trend analysis of miRNA expression profiles after exposure to atrazine in Yellow River Carp 
which were predicted to target Smad4, decreased after exposure to atrazine (Fig. 5, profile 0). The most abundant differentially-expressed miRNAs after exposure to atrazine in PG, juvenile ovary and juvenile testis were let-7a, miR-143, and miR-125b, all of which decreased significantly during atrazine exposure.

The above results indicate that these miRNAs may influence gonad development.

\section{Identification and Signalling analysis of target genes of differentially-expressed miRNA}

To identify potential targets of differentially-expressed miRNAs, involved in sex differentiation and development after atrazine exposure, we conducted target-gene prediction based on the common carp (C. carpio) genome sequence (http://www.carpbase.org/). A total of 26, 299 genes were predicted to be the possible targets of 4353 differentially-expressed miRNAs that were commonly expressed in all atrazine exposure samples. Two hundred thirty-nine annotated signalling pathways were identified totally, including at least 10 pathways that involved in the reproductive process, for example Wnt signalling, Notch signalling, transforming growth factor- $\beta$ (TGF- $\beta$ ) signalling, $\mathrm{p} 53$ signalling, steroid hormone biosynthesis, and estrogen signalling pathway. From the result, we found that the targets of 790 miRNAs belonged to the MAPK signalling pathway, which plays an important role in the process of spermatogenesis in the testis. In addition, MAPK signalling has been reported to be involved in the acrosome reaction in the female reproductive tract before fertilization of the ovum [55]. Wht signalling was reported to be involved in mammalian reproduction [56], and in zebrafish sex determination [57]. We detected 415 miRNA targets belonging to the Wnt signalling pathway, 30 belonging to NF-kappa $B$ signalling pathway, and 133 belonging to p53 signalling pathway. Wnt signalling pathway, NF-kappa $B$ signalling pathway and p53 signalling pathways were associated with sex differentiation in zebrafish [57]. Target genes predicted to belong to the three pathways in our study may be involved in sex differentiation and gonad development in Yellow River carp. Moreover, we identified 245 miRNA targets belonging to the TGF- $\beta$ signalling pathway, and 179 belonging to the Notch signalling pathway. In addition, we also identified 31 miRNA targets belonging to oestrogen signalling pathway, which may play an important role in hormone regulation.

To determine the key biological process of the putative target genes related to atrazine exposure, GO analysis was performed. The identified biological processes that the putative target genes were classified into include reproduction, reproductive process, response to stimulus, developmental process, and growth, which were all mechanisms related to sex differentiation and gonad development. The results showed possible relationships between atrazine, putative targets and gonad development, and suggested that atrazine may have effect on sex differentiation and gonad development.

We analysed the relationships between differentiallyexpressed miRNAs and their putative target genes. Foxl2, gsdf, sf1, dmrt and stat1 have been shown to be essential factors in early ovary differentiation [58, 59]. Smad4, atm, sox9, and smad3, which are also known to be responsible for gonad differentiation, were also analysed. We found that these genes were predicted to be the target genes of multiple miRNAs, and thus negatively regulated by these targets. Given the important roles of steroid hormones in sexual dimorphism and reproduction in fish, we analysed the relationships between miRNAs, including $h s d 11 b$ and $h s d 3 b$, mRNAs, and the steroid hormone biosynthesis pathway. Atrazine has endocrine-disrupting effects by altering the HPG axis [60]. We analysed genes that have critical roles in the regulation of the HPG axis including ER1, ER2, AR, and CYP19A1.

In the PG, a higher number of miRNAs targeting female-biased genes were down-regulated. MiR-135c which was significantly down-regulated by 2.21 -fold and 2.88 -fold after exposure to atrazine for $8 \mathrm{~h}$ and $24 \mathrm{~h}$, respectively, were predicted to target $E R$, foxl2, and CYP19A. Gsdf was predicted to be the target of miR-132a, miR-146a, miR-210, and miR-22a which were also downregulated. Our results indicated that atrazine can promote early gonad-determining genes by down-regulating miRNAs. MiR-205, which was predicted to target atm, $E G F, b c l 2, B M P 1$ (bone morphogenetic protein 1), was significantly up-regulated by 7.23 -fold for $8 \mathrm{~h}$ and 7.15 -fold for $24 \mathrm{~h}$, respectively. MiR-132a, which targeted dmrt2, was up-regulated by 1.22-fold after exposure to atrazine for $24 \mathrm{~h}$, but it was not at $8 \mathrm{~h}$. miR-499, which also targeted $d m r t 2$, was up-regulated by 1.46 -fold for $8 \mathrm{~h}$ and 1.57 -fold for $24 \mathrm{~h}$, respectively. After exposure to atrazine for $24 \mathrm{~h}$, miR-202x, and miR-374-y, which were predicted to target smad3, were up-regulated and down-regulated, respectively. $H s d 11 b$ was predicted to be the target of miR-216- $\mathrm{x}$ and miR-342-y. Hsd3b was the predicted target of let-7-z. Stat1 was the predicted target of miR-135c and miR-430, Sf1 of miR-154-y and miR-3958-y, and Sox9 of miR-499. The above results indicate the possible roles of the differentially-expressed miRNAs in PG, after exposure to atrazine during gonad differentiation.

In juvenile ovary, miR-21, which was significantly upregulated by 2.18 -fold after exposure to atrazine for $24 \mathrm{~h}$, was predicted to target $A R$ and $a t m$. MiR-101b, which was predicted to target $s f 1$, was significantly downregulated by 1.01 -fold. MiR-132a, which was significantly up-regulated by 1.08-fold after exposure to atrazine for $8 \mathrm{~h}$, was predicted to target $A R, d m r t 2, g s d f$, and $a t m$. 
Smad4 was predicted to target novel-m0048-5p. Hsd11b was predicted to target novel-m0305-3p. Hsd3b was predicted to be the target of miR-410-x. Stat1 was the predicted target of miR-192, CYP19A of miR-203a and novel-m0527-3p, and Sox9 of novel-m0011-5p.

In juvenile testis, miR-181b, and miR-181c, which were significantly up-regulated by 1.04 -fold and 1.41 -fold, respectively, after exposure to atrazine for $24 \mathrm{~h}$, was predicted to target $d m r t 2$ and atm. miR-146a, which was predicted to target $g s d f$ was significantly up-regulated by 1.70-fold. MiR-132a, which was significantly downregulated by 1.28 -fold, was predicted to target $E R$. Smad4 was predicted to target miR-200b. Hsd11b was predicted to target novel-m0305-3p. Hsd3b was predicted to be the target of miR-410-x. Stat1 was the predicted target of miR-192, CYP19A of miR-203b-3p and novel-m0693-5p, and Sox9 of novel-m0081-5p. These results indicate that atrazine promotes the biosynthesis of steroid hormone by altering the miRNAs.

These differentially-expressed miRNAs were also predicted to play key roles in many reproductive biology pathways, including TGF- $\beta$ receptor signalling, Wnt signalling, steroid metabolic processes, and cell differentiation. Moreover after exposure to atrazine for $24 \mathrm{~h}$, the predicted target genes of the differentially-expressed miRNAs of PG included hsd3, lemd3, grk6, ccna1, pcna, smad4, tbx6, GATA, cyp51a1,RBMS1, zranb1, and prosapip1, and some of which, such as hsd3 and cyp51a1, are gonad development-related genes. Besides, many other miRNAs were predicted to target genes involved in reproductive processes. MiR-205 and miR-135c were predicted to be the target of $b c l 2$ and notch2, which belong to the TGF- $\beta$ signalling and Notch signalling pathways, respectively. MiR-205 was predicted to target inhibin beta $A$ chain and $p d k 1$, which are related to female gonad development, and TGF- $\beta$ signalling, respectively. The results indicate that the differentially-expressed miRNAs perform some of the possible roles of in gonad reproductive processes. However, the specific mechanism needs further experimental verification.

\section{Discussion}

MiRNAs are involved in diverse biogenesis pathways and have versatile regulatory functions in differentiation, proliferation, and apoptosis [61]. To date only a limited number of studies have investigated miRNA expression alterations in response to exposure to endocrine-disrupting chemical in fish and humans [62-65]. There are only few reports on the miRNA profiling of fish, in response to atrazine exposure, mainly focus on zebrafish and no reports in common carp [17, 18, 21, 22, 26, 66, 67]. The investigation into the adverse effects of atrazine exposure on miRNAs is important to reveal the molecular mechanism of gonad differentiation. In the present study, we assessed the potential effects of atrazine on miRNAs in the reproductive system at two developmental stages (PG and II-stage gonad) of Yellow River carp. Primordial germ cell formation is a crucial stage of gonad differentiation, and II-stage gonad is the stage of evident sex differentiation. Comparative analysis of miRNA expression profiles at these two important stages, after exposure to atrazine, is helpful to identify miRNAs that play important roles in gonad differentiation.

In this study, atrazine exposure resulted in changes in the sex ratio of carp, the ratio of female increased with the increase of concentration. In addition, atrazine exposure resulted in significant expression alterations of various miRNAs. Atrazine exposure for $24 \mathrm{~h}$ caused more alterations in the expression of miRNAs than exposure for $8 \mathrm{~h}$. Atrazine exposure for $24 \mathrm{~h}$ caused more alteration in miRNA expression in juvenile testis than in juvenile ovary. It is thus clear that acute and short-time exposure to atrazine during development can produce adverse effects, as has been suggested before [68].

Several studies in amphibians have suggested that atrazine is associated with feminization of males in the wild $[20,69]$. In field studies, atrazine has repeatedly been associated with the presence of feminized secondary sex characteristics in male frogs [70]. In fish, atrazine causes degeneration of interstitial tissue in the testes [66] and feminizes the gonads of developing male teleost fish [71]. In addition, embryonic atrazine exposure alters the expression of zebrafish and human miRNAs known to play a role in angiogenesis, cancer, neuronal development, differentiation, and maturation [22]. In our study, atrazine exposure altered the expression of carp miRNAs that play a role in gonad differentiation and gonad development. A number of miRNAs, such as let-7, miR-21, miR-101, and miR-124 that are highly expressed in silver carp and adult bighead carp were significantly altered in our study [72].

Our results suggest that miR-181a, miR-21, miR-430, let-7, and miR-143 may involve in the process of gonad differentiation and development in carp.

Several studies have shown that miR-21 play an important role in gonad differentiation and development. A study reported that in cattle miR-21 was significantly up-regulated in the ovary (relative to testis), which suggest that miR-21 may play a regulatory role in female physiology [73]. Other study showed that miR-21 also plays a certain role in preventing periovulatory granulosa cells apoptosis when they transit into luteal cells [74]. In addition, has-miR-21 was also shown to be increased by ovarian steroids in mouse granulosa cells, glandular epithelial cells, and human endometrial stromal cells $[75,76]$. In the present study, atrazine exposure did not change the expression of miR-21 in the PG after atrazine exposure, but induced its up-regulation in juvenile ovary and down-regulation in juvenile testis. 
The predicted targets of miR-21 included genes in the $T G F-\beta$, B-cell receptor, $M A P K$, and apoptotic pathways. This observation suggests that miR-21 may play crucial roles in ovary development, gonad differentiation [77], and endocrine regulation $[55,78]$. The predicted target genes of miR-21 in our study were $A R$ and atm.

Let-7 was another family of miRNAs with altered expression by atrazine exposure. The let- 7 family was first discovered and characterized in Caenorhabditis elegans, and plays an important role in regulating late developmental events by down-regulating lin-41, and possibly other genes [79]. Let-7 was significantly up-regulated after atrazine exposure in the PG and juvenile testis. The predicted target genes of let-7 in our study were sox 9 and atm.

The miR-430 family was reported to have important role in embryonic morphogenesis and clearance of maternal mRNAs, and it's highly expressed during early zebrafish development [67, 80-82]. Study has shown that miR-430 target chemokine signalling to ensure accurate migration of primordial germ cells [83]. In our study and miR-430 was down-regulated in PG but not in juvenile gonad, which indicates that miR-430 has an important role in early gonad differentiation of Yellow River carp.

Several reports showed that miR-143 is highly expressed in the juvenile ovary; it is a dominant miRNA in ovaries in yellow catfish, pigs, and cattle [84, 85]. In this study, miR-143 was highly expressed in the ovary of common carp exposed to atrazine, which is in keeping with previous reports.

The miR-181a family is abundantly expressed in the gonads of tilapia [86], mice [87], and humans [88]. It was down-regulated in juvenile ovary in the present study. Overall, above results suggest that miR-21, let-7, miR-430, miR-181a, and miR-143 may play vital roles in gonad development process in Yellow River carp.

Differentially expressed miRNAs showed a variety of expression patterns at different development stages. Among the 8 different expression patterns, two patterns are worthy of attention, involving miRNAs with expression levels that either up-regulated or down-regulated significantly after atrazine exposure. MiRNAs whose expression either increased or decreased significantly after atrazine exposure may be direct regulators of gonad differentiation. Samples with the highest number of miRNAs with altered expression were the PG and juvenile ovary exposed to atrazine for $8 \mathrm{~h}$ or $24 \mathrm{~h}$. The number of decreased miRNAs was 1056 in PG, including miRNAs which targets were female-biased. Because miRNAs are negatively correlated with its target genes, this observation suggests that atrazine promotes the expression of female-biased genes by decreasing specific miRNAs in PG, which would result in the differentiation of the gonad to the female phenotype. The juvenile ovaries exposed to atrazine had the highest number of upregulated miRNAs, including miRNAs whose targets are male-biased. It is thus possible that atrazine represses the expression of male-biased genes by increasing specific miRNAs in juvenile ovary.

The juvenile testis exposed to atrazine had the highest number of miRNAs with altered expression, indicating that this tissue was more sensitive to atrazine, possibly leading to the feminization of males. This observation suggests that these miRNAs may have an important function in the timing of gonad differentiation and development.

The result of target prediction showed that many of the miRNA targets that we identified were involved in gonad differentiation.

Among these predicted target genes, dmrt, gsdf, and sox 9 have been identified as sex-determining genes in fish $[89,90]$. For example, $H s d 11 b$ and $h s d 3 b$ which encoding key enzymes in the steroid hormone biosynthesis pathway, may involved in steroid hormone synthesis, sex differentiation, and gonad function, and may play a vital role in developmental timing. However, further studies are needed to confirm the interactions and functions of miRNA and target genes. In addition, the results also show that atrazine has oestrogenic effects down-regulating male-biased genes (such as dmrt and atm) through specific miRNAs up-regulation, and up-regulating female-biased genes (such as foxl2) through specific miRNAs down-regulation.

Previous studies showed that atrazine exposure can significantly reduce synthesis, secretion, and the circulating levels of androgens in fish [66, 91], amphibians $[20,11]$, reptiles [92], and mammals [93, 94], and also in birds to a lower extent [95]. The endocrine-disrupting effects of atrazine are primarily due to alterations of the HPG axis [17, 25, 26, 24, 23]. However, atrazine's mechanism of action is not well-understood, it has been proposed that atrazine up-regulate aromatase expression [96-99]. Aromatase up-regulation leads to increased conversion of androgens into oestrogens [100]. In the present study, we analysed genes that regulate hormone biosynthesis in the HPG axis, including $E R 1, E R 2, A R$, and CYP19A1. MiR-122, which targets ER1 and ER2, was down-regulated by atrazine. MiR-21, which targets $A R$ was up-regulated in PG by atrazine. MiR-203a, which targets CYP19A1, was down-regulated in PG by atrazine. Our results indicate that atrazine possibly can up-regulate aromatase expression through specific miRNAs, which is consistent with previous studies.

We tested the hypothesis that atrazine has endocrinedisrupting effects by altering genes of the HPG axis through its corresponding miRNAs. In the PG, atrazine affects sex differentiation mainly through altering upstream genes involved in gonad differentiation. In juvenile ovary or testis, atrazine affects the gonad development mainly through 
altering hormone generation and the expression of hormone receptor genes. Further studies are needed to investigate the mechanisms and roles of miRNAs in the regulation of genes during gonad differentiation and development.

\section{Conclusions}

Atrazine is widely used in agriculture and is a known endocrine disrupting chemical, but the effects of atrazine on the reproduction of carp, especially miRNA have not been investigated. In this study, the effects of atrazine on the reproduction of carp, especially miRNA were analyzed. Atrazine exposure can affect the sex ratio, and caused significant alterations in miRNAs expression at the crucial stages of carp gonad development. Target genes of differentially-expressed miRNAs are key factors in early ovary differentiation or play an important role in the formation of germ cells. Our results indicate that atrazine promoted the expression of female-biased genes by decreasing miRNAs in primordial gonad. In addition, our results indicate that atrazine can up-regulate aromatase expression through miRNAs, which supports the hypothesis that atrazine has endocrine-disrupting activity by altering the expression of genes of the HypothalamusPituitary-Gonad axis through its corresponding miRNAs.

\section{Methods}

\section{Chemicals}

Atrazine (purity >98\%) was purchased from Beijing Dezhong-Venture Pharmaceutical Technology Development Co., Ltd. (Beijing, China). As atrazine has low solubility in water, the stock solutions and dilutions were prepared in acetone (Fisher Scientific, USA) and stored at $4{ }^{\circ} \mathrm{C}$.

\section{Fish samples}

The sample fish (Yellow River carp) used in this study were obtained from the aquaculture facilities of Henan Normal University and maintained at the genetics laboratory (Henan normal university, Xinxiang Henan province, China) in flow-through water tanks with a constant temperature of $25 \pm 1{ }^{\circ} \mathrm{C}$. Embryos were obtained by natural spawning and larvae were cultured in embryo medium following standard procedures. Fry were fed two times daily with commercial flake food. All investigations in this study were performed according to the Animal Experimental Guidelines of the Ethical Committee of the University of China.

The experimental sample of miRNA expression profile included gonads from two different developmental stages. According to the results of our previous studies, primordial gonad samples were collected from larvae at 45 days post-hatching [49]. The original reproductive gonad was dissected under a microscope, and samples from 50 fish were mixed after confirmation by histological section. Samples of juvenile gonad were collected from 30 fish 80 days post-hatching. Stage II ovaries and testis were confirmed with histological sections.

\section{Atrazine exposure}

At 5 days post-hatch (dph), fry were divided into several groups, held in the water containing atrazine at a concentration of $0,4.28,42.8$, or $428 \mu \mathrm{g} / \mathrm{L}$. To avoid metabolic and microbial breakdown of atrazine, half of the water was removed and replaced every 3 days with fresh atrazine-contaminated water. At 130 dph, 100 fish from each group were randomly selected for histological examination of the sex.

Samples of two different stages including primordial gonad and juvenile gonad (ovary and testis) were cultured at $28^{\circ} \mathrm{C}$ in a humidified $10 \% \mathrm{CO}_{2}$ atmosphere in Dulbecco's modified eagle medium supplemented with $10 \%$ foetal bovine serum (Gibco, Life Technologies) [101, 102]. Culture medium was renewed every 2 days. Before gonad collection the fish were anesthetized by immersion in $50 \mu \mathrm{g} / \mathrm{ml}$ of tricaine methane sulfonate (MS-222). And at the end of the experiment fish were euthanized by immersion into a $0.5 \mathrm{~g} / \mathrm{L}$ tricaine solution (Sigma-Aldrich). For atrazine exposure experiments, cells were seeded in 24-well plates and allowed to proliferate for $48 \mathrm{~h}$. Then samples were treated with $428 \mu \mathrm{g} / \mathrm{L}$ of atrazine for $24 \mathrm{~h}$. Three replicates were set for each treatment, as well as for the unexposed control. Samples were collected at $8 \mathrm{~h}$ and $24 \mathrm{~h}$ post-treatment, and were immediately frozen in liquid nitrogen for further use.

\section{RNA isolation}

Total RNA was extracted from each sample separately using TRIzol reagent (Invitrogen, Carlsbad, CA, USA) according to the instructions. The quantity and purity of total RNA were checked using the Agilent 2100 Bioanalyzer system (Santa Clara, CA, USA) and by denaturing gel electrophoresis. The total RNAs were then stored at $-80^{\circ} \mathrm{C}$ for further use.

\section{Small-RNA library construction and sequencing}

Small-RNA libraries were generated from the nine samples of Yellow River carp: primordial gonad control (PG-CK), primordial gonad exposed to atrazine for $8 \mathrm{~h}$ (PG-A8h), primordial gonad exposed to atrazine for $24 \mathrm{~h}$ (PG-A24h), juvenile ovary control (IIC-CK), juvenile ovary exposed to atrazine for $8 \mathrm{~h}$ (IIC-A8h), juvenile ovary exposed to atrazine for $24 \mathrm{~h}$ (IIC-A24h), juvenile testis control (IIX-CK), juvenile testis exposed to atrazine for $8 \mathrm{~h}$ (IIXA8h), juvenile testis exposed to atrazine for $24 \mathrm{~h}$ (IIX-A24h) . Small-RNA libraries were generated using the mirVanaTM mircoRNA Isolation Kit (Ambion, USA), according to the manufacturer's instructions. Small-RNA libraries were prepared from three biological replicates for each sample.

Total RNA was ligated with $3^{\prime}$ and 5' RNA adaptors. Fragments with adaptors on both ends were enriched by 
PCR after reverse transcription, as described previously [49]. The resulting cDNAs were purified and enriched with $6 \%$ denaturing polyacrylamide gel electrophoresis to isolate the fractions of the expected size and to eliminate unincorporated primers, primer dimer products, and dimerized adaptors [49]. Finally, the nine resulting RNA libraries were sequenced using an Illumina/Solexa Genome Analyzer, at Guangzhou Genedenovo Biotech Company (Guangzhou, China).

\section{Sequencing data analysis}

As we described previously [49], after remove low quality reads, adaptor sequences and adaptor trimming, reads of 16-35 nt in length were kept for further bioinformatic analysis. Using Bowtie (version 1.1.0), the remaining reads were mapped to the $C$. carpio genome with a tolerance of zero mismatches in the seed sequence. By blasting against the Rfam (11.0, http://rfam.xfam.org) and GenBank (http:// www.blast.nvbi.nlm.nih.gov/) databases, the reads mapped to the $C$. carpio genome were then analysed to annotate snRNA, tRNA, rRNA, snoRNA, and non-coding RNA sequences. The remaining sequences were identified as the conserved miRNAs in carp by blasting against miRBase 21.0 allowing no more than two mismatches. Existing carp miRNAs referring to C. carpio miRNA were included in the miRBase with no base mismatch. The sequences that did not match existing or conserved miRNAs were used to identify potentially novel miRNA candidates $[103,104]$. Novel miRNA candidates were identified by folding the flanking genome sequence of unique small RNAs using MIREAP (https://sourceforge.net/projects/mireap/). The enrichment level of each miRNA was identified by counting the number of reads in each sample. To identify differentially-expressed miRNAs within the nine libraries, the frequency of miRNA counts was normalized as transcripts per million (TPM). The TPM values were calculated as follows: normalized expression, TPM $=($ actual miRNA count/number of total clean reads) $\times 1,000,000$. Only the miRNAs with over 2-fold changes in the two compared samples were considered differentially-expressed miRNAs $(P<0.05)$ [105]. A positive value represents up-regulation of a miRNA, while a negative value indicates down-regulation.

\section{Prediction of miRNA targets}

Targets of miRNAs were predicted using three softwares, including miRanda (v3.3a), RNAhybrid (v2.1.2) + svm light (v6.01) and Targetscan. The overlap of the predicted results was considered to represent the final result of predicted target mRNAs.

\section{Gene ontology (GO) and pathway analysis of atrazine-responsive mRNA targets}

Pathway analysis of the predicted target mRNAs was performed using the Kyoto Encyclopedia of Genes and
Genomes (KEGG) pathway database (http://www.genome. jp/kegg/pathway.html) [106]. To classify the selected genes into groups with similar patterns of expression, each gene was assigned to an appropriate category, according to its main cellular function. To determine the biological phenomena target mRNAs were involved in, the DAVID (http://david.abcc.ncifcrf.gov/home.jsp) functional annotation clustering tool was used.

\section{qPCR for validation of miRNAs}

The expression profiles of six randomly-selected miRNAs were investigated with $\mathrm{qPCR}$ to validate their expression changes. Total RNA (500 ng) was converted to cDNA using miScript reverse transcriptase mix (Qiagen, Valencia, CA, USA) according to the manufacturer's instructions. qPCR was carried out using an Applied Biosystems 7300 Real-Time PCR System according to the standard protocol. CDNA samples were diluted to $1: 150 ; 5 \mu \mathrm{L}$ were used for each real-time PCR reaction. The $20-\mu \mathrm{L}$ PCR mixture included $10 \mu \mathrm{L}$ SYBR Premix Taq $(2 \times), 0.4 \mu \mathrm{L}$ miRNAspecific forward primers $(10 \mu \mathrm{M}), 0.4 \mu \mathrm{L}$ miScript universal primer $(10 \mu \mathrm{M})$, and $1 \mu \mathrm{L}$ PCR template (cDNA). The PCR thermal program was $50^{\circ} \mathrm{C}$ for $2 \mathrm{~min}$, followed by 40 cycles of $95^{\circ} \mathrm{C}$ for $2 \mathrm{~min}, 95^{\circ} \mathrm{C}$ for $15 \mathrm{~s}$, and $60^{\circ} \mathrm{C}$ for $30 \mathrm{~s}$. Melting curve analysis was performed after amplification. Standard curves for endogenous control and for all miRNAs were constructed using serial dilutions of a pooled cDNA sample. Standard curves were used to determine the quantity of the selected miRNAs and reference genes. Relative miRNA expression levels were calculated using the $2^{-\Delta \Delta C t}$ method. Each sample was run in triplicate. SnRNA 46 was used as an endogenous control for qPCR of miRNAs.

\section{Additional files}

Additional file 1: Differentially expressed miRNAs after exposed to atrazine. (XLS 510 kb)

Additional file 2: Predicted target genes of differentially expressed miRNAs and target genes associated with significantly enriched GO terms after exposed to atrazine. (XLS 80605 kb)

Additional file 3: Differentially expressed mRNAs of PGC stage after exposed to atrazine for $8 \mathrm{~h}$. (XLS $14039 \mathrm{~kb}$ )

Additional file 4: Differentially expressed mRNAs of PGC stage after exposed to atrazine for $24 \mathrm{~h}$. (XLS $13978 \mathrm{~kb}$ )

Additional file 5: Differentially expressed mRNAs of juvenile ovary after exposed to atrazine for $8 \mathrm{~h}$. (XLS $20365 \mathrm{~kb}$ )

Additional file 6: Differentially expressed mRNAs of juvenile ovary after exposed to atrazine for $24 \mathrm{~h}$. (XLS $20271 \mathrm{~kb}$ )

Additional file 7: Differentially expressed mRNAs of juvenile testis after exposed to atrazine for $8 \mathrm{~h}$. (XLS $24312 \mathrm{~kb}$ )

Additional file 8: Differentially expressed mRNAs of juvenile testis after exposed to atrazine for $24 \mathrm{~h}$. (XLS $24795 \mathrm{~kb}$ ) 


\section{Authors' contributions}

FW performed the experiments, analyzed the data, and drafted the manuscript. QWY and WJZ participated in the sample collection, performed the experiments, and analyzed the data. QYD and ZJC conceived the project, analyzed the data, and revised the manuscript. All authors read and approved the final manuscript for publication.

\section{Funding}

This work was supported by the National Natural Science Foundation of China (NO. U1204329), the Henan Scientific and Technological Research Projects (NO. 172102110098), the Henan Scientific and Technological Research Projects (NO. 142300410164). The funding bodies had no role in the design of the study and collection, analysis, and interpretation of data and in writing the manuscript.

\section{Availability of data and materials}

The deep sequencing data sets generated in this project and supporting the results of this article are included within the article and its Additional files 1 , $2,3,4,5,6,7$ and 8 .

\section{Ethics approval and consent to participate}

The Yellow River carp used in this study were obtained from the aquaculture base of Henan Normal University and cultured in our own laboratory, and all fish were anesthetized by immersion in $50 \mathrm{\mu g} / \mathrm{ml}$ of tricaine methane sulfonate (MS-222), and at the end of the experiment fish were euthanized by immersion into a $0.5 \mathrm{~g} / \mathrm{L}$ tricaine solution (Sigma-Aldrich). The fish were cared for according to the Regulations for the Administration of Affairs Concerning Experimental Animals for the Science and Technology Bureau of China throughout the study, and the experimental protocols were approved by the Animal Management Committee of Henan Provincial Laboratory.

\section{Consent for publication}

Not applicable.

\section{Competing interests}

The authors declare that they have no competing interests.

Received: 22 October 2018 Accepted: 11 June 2019

Published online: 17 July 2019

\section{References}

1. Devlin RH, Nagahama Y. Sex determination and sex differentiation in fish: an overview of genetic, physiological, and environmental influence. Aquaculture. 2002;208:191-364

2. Colborn T. Developmental effects of endocrine-disrupting chemicals in wildlife and humans. Environ Health Perspect. 1993;101:378.

3. Corcoran J, Winter MJ, Tyler CR. Pharmaceuticals in the aquatic environment: a critical review of the evidence for health effects in fish. Crit Rev Toxicol. 2010;40:287-304.

4. Gianessi L \& Sankula S. The value of herbicides in U.S. crop production. National Center for food and agricultural policy. 2003. Retrieved from http:// www.croplifefoundation.org.

5. Barr DB, Panuwet P, Nguyen JV, Udunka S, Needham LL. Assessing exposure to atrazine and its metabolites using biomonitoring. Environ Health Perspect. 2007;115:1474-8.

6. Eldridge JC, Stevens JT, Breckenridge CB. Atrazine interaction with estrogen expression systems. Rev Environ Contam Toxicol. 2008;196:147-60.

7. Solomon KR, Carr JA, Du Preez LH, Giesy JP, Kendall RJ, Smith EE, et al. Effects of atrazine on fish, amphibians, and aquatic reptiles: a critical review. Crit Rev Toxicol. 2008;38:721-72.

8. U.S. Environmental Protection Agency. Atrazine, simazine, and cyanizine. Notice of initiation of special review. Fed Reg. 1994;59:60412-43.

9. Freeman JL, Rayburn AL. Developmental impact of atrazine on metamorphing Xenopus laevis as revealed by nuclear analysis and morphology. Environ Toxicol. 2005;24(7):256-63.

10. Cooper RL, Laws SC, Das PC, Narotsky MG, Goldman JM, Tyrey EL, Stoker TE. Atrazine and reproductive function: mode and mechanism of action studies. Birth Defects Res B Dev Reprod Toxicol. 2007;80(2):98-112.

11. Hayes TB, Khoury V, Narayan A, Nazir M, Park A, Brown T, Gallipeau S. Atrazine induces complete feminization and chemical castration in male
African clawed frogs (Xenopus laevis). Proc Natl Acad Sci U S A. 2010;107(10):4612-7.

12. Cragin LA, Kesner JS, Bachand AM, Barr DB, Meadows JW, Krieg EF, Reif JS. Menstrual cycle characteristics and reproductive hormone levels in women exposed to atrazine in drinking water. Environ Res. 2011;111(8):1293-301.

13. Pogrmic K, Fa S, Dakic V, Kaisarevic S, Kovacevic R. Atrazine oral exposure of peripubertal male rats downregulates steroidogenesis gene expression in Leydig cells. Toxicol Sci. 2009;111:189-97.

14. Pogrmic-Majkic K, Fa S, Dakic V, Kaisarevic S, Kovacevic R. Upregulation of peripubertal rat Leydig cell steroidogenesis following $24 \mathrm{~h}$ in vitro and in vivo exposure to atrazine. Toxicol Sci. 2010;118:52-60.

15. Kucka M, Pogrmic-Majkic K, Fa S, Stojilkovic SS, Kovacevic R. Atrazine acts as an endocrine disrupter by inhibiting CAMP-specific phosphodiesterase-4. Toxicol Appl Pharmacol. 2012;265:19-26.

16. Karmaus AL, Zacharewski TR. Atrazine mediated disruption of steroidogenesis in BLTK1 murine Leydig cells. Toxicol Sci. 2015;148:544-54.

17. Wirbisky SE, Weber GJ, Sepúlveda MS, Lin TS, Jannasch AS, Freeman JL. An embryonic atrazine exposure results in reproductive dysfunction in adult zebrafish and morphological alterations in their offspring. Sci Rep. 2016a;6:21337.

18. Wirbisky SE, Sepúlveda MS, Weber GJ, Jannasch AS, Horzmann KA, Freeman JL. Emryonic atrazine exposure elicits alterations in genes associated with neuroendocrine function in adult male zebrafish. Toxicol Sci. 2016b;153:149-64.

19. Tevera-Mendoza L, Ruby S, Brousseau P, Fournier M, Cyr D, Marcogliese D. Response of the amphibian tadpole (Xenopus laevis) to atrazine during sexual differentiation of the testis. Environ Toxicol Chem. 2002;21:527-31.

20. Hayes TB, et al. Atrazine-induced hermaphroditism at $0.1 \mathrm{ppb}$ in American leopard frogs (Rana pipiens): laboratory and field evidence. Environ Health Perspect. 2002:111:568-75.

21. Suzawa M, Ingraham $H$. The herbicide atrazine activates endocrine gene networks via non-steroidal NR5A nuclear receptors in fish and mammalian cells. PLoS One. 2008;3:2117.

22. Sara E. Wirbisky, el al. Embryonic atrazine exposure alters zebrafish and human miRNAs associated with angiogenesis, cancer, and neurodevelopment. Food Chem Toxicol. 2016:98:25-33.

23. Foradori CD, Hinds LR, Hanneman WH, Legare ME, Clay CM, Handa RJ. Atrazine inhibits pulsatile luteinizing hormone release without altering pituitary sensitivity to a gonadotropin-releasing hormone receptor agonist in female Wistar rats. Biol Reprod. 2009;1:40-5.

24. Cooper RL, Stoker TE, Tyrey L, Goldman JM, McElroy WK. Atrazine disrupts the hypothalamic control of pituitary-ovarian function. Toxicol Sci. 2000;53:297-307.

25. Foradori $C D$, Zimmerman $A D$, Hinds $L R$, Zuloaga $K L$, Breckenridge $C B$, Handa RJ. Atrazine inhibits pulsatile gonadotropin-releasing hormone $(\mathrm{GnRH})$ release without altering GnRH messenger RNA or protein levels in the female rat. Biol Reprod. 2013;88:1-7.

26. Weber GJ, Sepúlveda MS, Peterson SM, Lewis SL, Freeman JL. Transcriptome alterations following developmental atrazine exposure in zebrafish are associated with disruption of neuroendocrine and reproductive system function, cell cycle, and carcinogenesis. Toxicol Sci. 2013;132:458-66.

27. Bartel DP. MicroRNAs: genomics, biogenesis, mechanism, and function. Cell. 2004;116(2):281-97.

28. He L, Hannon GJ. MicroRNAs: small RNAs with a big role in gene regulation. Nat Rev Genet. 2004;5:522-31.

29. Krol J, Loedige I, Filipowicz W. The widespread regulation of microRNA biogenesis, function and decay. Nat Rev Genet. 2010;11:597-610.

30. Brennecke J, Hipfner DR, Stark A, Russell RB, Cohen SM. Bantam encodes a developmentally regulated microRNA that controls cell proliferation and regulates the proapoptotic gene hid in Drosophila. Cell. 2003;113:25-36.

31. Xu P, Vernooy SY, Guo M, Hay BA. The Drosophila microRNA mir-14 suppress cell death and is required for normal fat metabolism. Curr Biol. 2003;13:790-5.

32. Hwang HW, Mendell JT. MicroRNAs in cell proliferation, cell death, and tumori-genesis. Br J Cancer. 2006;94:776-80.

33. Pedersen IM, Cheng G, Wieland S, Volinia S, Croce CM, Chisari FV, David M. Interferon modulation of cellular microRNAs as an antiviral mechanism. Nature 200. 449;2007:919-22.

34. Ro S, Song R, Park C, Zheng H, Sanders KM, Yan W. Cloning and expression profiling of small RNAs expressed in the mouse ovary. RNA. 2007;13:2366-80. 
35. Jardim MJ, Fry RC, Jaspers I, Dailey L, Diaz-Sanchez D. Disruption of microRNA expression in human airway cells by diesel exhaust particles is linked to tumorigenesis-associated pathways. Environ Health Perspect. 2009;117:1745-51.

36. Zhang B, Pan X. RDX induces aberrant expression of microRNAs in mouse brain and liver. Environ Health Perspect. 2009;117:231-40.

37. Rager JE, Smeester L, Ilona J, Sexton KG, Fry RC. Epigenetic changes induced by air toxics: formaldehyde exposure alters miRNA expression profiles in human lung cells. Environ Health Perspect. 2011;119:494-500.

38. Li J, Wu Z, Cheng F, Li W, Liu G, Tang Y. Computational prediction of microRNA networks incorporating environmental toxicity and disease etiology. Sci Rep. 2014;4:5576.

39. Qiu C, Chen G, Cui Q. Towards the understanding of microRNA and environmental factor interactions and their relationships to human diseases. Sci Rep. 2012;2:318.

40. Izzotti A, Pulliero A. The effects of environmental chemical carcinogens on the microRNA machinery. Int J Hyg Environ Health. 2014;217:601-27.

41. Ray PD, Yosim A, Fry RC. Incorporating epigenetic data into the risk assessment process for the toxic metals arsenic, cadmium, chromium, lead, and mercury: strategies and challenges. Front Genet. 2014;5:Article 201.

42. Xu P, Zhang XF, Wang XM. Genome sequence and genetic diversity of the common carp, Cyprinus carpio. Nat Genet. 2014;46(11):1212-9.

43. Ji PF, Liu GM, Xu J, Wang XM, Li JT, Zhao ZX, Zhang XF, Zhang Y, Xu P, Sun XW. Characterization of common carp transcriptome: sequencing, De novo assembly, annotation and comparative genomics. PLoS One. 2012;7:e35152.

44. Jiang YL, Feng SS, Zhang SH, Liu H, Feng JX, Mu XD, Sun XW, Xu P. Transcriptome signatures in common carp spleen in response to Aeromonas hydrophila infection. Fish Shellfish Immunol. 2016;57:41-8.

45. Xu J, Zhao ZX, Zhang XF, Zheng XH, Li JT, Jiang YL, et al. Development and evaluation of the first high-throughput SNP array for common carp (Cyprinus carpio). BMC Genomics. 2014;15:307.

46. Zhu YP, Xue W, Wang JT, Wan YM, Wang SL, Xu P, et al. Identification of common carp (Cyprinus carpio) microRNAs and microRNA-related SNPS. BMC Genomics. 2012;13:413.

47. Gui J, Zhu Z. Molecular basis and genetic improvement of economically important traits in aquaculture animals. Chin Sci Bull. 2012:57(15):1751-60.

48. Mei J, Gui JF. Genetic basis and biotechnological manipulation of sexual dimorphism and sex determination in fish. Sci China Life Sci. 2015;8(2):124-36.

49. Wang F, Jia YF, Wang P, Yang QW, Du QY, Chang ZJ. Identification and profiling of Cyprinus carpio microRNAs during ovary differentiation by deep sequencing. BMC Genomics. 2017;18:333.

50. Jia YF, Nan P, Zhang WW, Wang F, Zhang RH, Liang TT, Ji XL, Du QY, Chang ZJ. Transcriptome analysis of three critical periods of ovarian development in Yellow River carp (Cyprinus carpio). Theriogenology. 2017;105:15-26.

51. Wirbisky SE, Weber GJ, Schlotman KE, Sepúlveda MS, Freeman JL. Embryonic atrazine exposure alters zebrafish and human miRNAs associated with angiogenesis, cancer, and neurodevelopment. Food Chem Toxicol. 2016;98(Pt A:25-33.

52. Klattenhoff $C$, Theurkauf W. Biogenesis and germline functions of piRNAs. Development. 2008;135:3-9.

53. Grentzinger T, Armenise C, Brun C, Mugat B, Serrano V, Pelisson A, Chambeyron S. PiRNA-mediated transgenerational inheritance of an acquired trait. Genome Res. 2012;22:1877-88.

54. Kawaoka S, Mitsutake H, Kiuchi T, Kobayashi M, Yoshikawa M, Suzuki Y, Sugano S, Shimada T, Kobayashi J, Tomari Y. Katsuma T. a role for transcription from a piRNA cluster in de novo piRNA production. RNA 2012;18:265-73

55. Huang J, Ju Z, Li Q, Hou Q, Wang C, Li J, Li R, Wang L, Sun T, Hang S, et al. Solexa sequencing of novel and differentially expressed microRNAs in testicular and ovarian tissues in Holstein cattle. Int J Biol Sci. 2011;7:1016-26.

56. Kobayashi A, Stewart CA, Wang Y, et al. $\beta$-Catenin is essential for Mullerian duct regression during male sexual differentiation. Development epub.

57. Chang W, et al. Zebrafish sex: a complicated affair. Briefings in functional genomics. 2011. 2013;13:172-87.

58. Nagahama Y. 17 alpha, 20 beta-dihydroxy-4-pregnen-3-one, a maturation inducing hormone in fish oocytes: mechanisms of synthesis and action. Steroids. 1997;62(1):190-6.

59. Ijiri S, Kaneko H, Kobayashi T, Wang DS, Sakai F, Paul-Prasanth B, Nakamura $M$, Nagahama Y. Sexual dimorphic expression of genes in gonads during early differentiation of a teleost fish, the Nile tilapia Oreochromis niloticus. Biol Reprod. 2008;78(2):333-41.
60. Trentacoste SV, Friedmann AS, Youker RT, Breckenridge CB, Zirkin BR. Atrazine effects on testosterone levels and androgen-dependent reproductive organs in peripubertal male rats. J Androl. 2001;22:142-8.

61. Bartel D. MicroRNAs: target recognition and regulatory functions. Cell. 2009:136:215-333

62. Hsu WL, Chen JY, Chien YC, Liu MY, et al. Independent effect of EBV and cigarette smoking on nasopharyngeal carcinorna:a 20-year follow-up study on 9,622 males without family history in Taiwan. Cancer Epidemiol Biomark Prev. 2009;18(4):1218-26.

63. Avissar-Whiting M, Veiga KR, Uhl KM, et al. Bisphenol a exposure leads to specific microRNA alterations in placental cells. Reprod Toxicol. 2010;29:401-6.

64. Tilghman SL, Bratton MR, Segar HC, et al. Endocrine disruptor regulation of microRNA expression in breast carcinoma cells. PLoS One. 2012:7:32754.

65. Veiga-Lopez A, Luense L, Christenson LK, et al. Developmental programming gestational bisphenol-a treatment alters trajectory of fetal ovarian gene expression. Endocrinology. 2013;54(5):1873-84.

66. Spano $L$, et al. Effects of atrazine on sex steroid dynamics, plasma vitellogenin concentration and gonad development in adult goldfish (Carassius auratus). Aquat Toxicol (Amsterdam). 2004;66(4):369-79.

67. Choi WY, Giraldez AJ, Schier AF. Target protectors reveal dampening and balancing of nodal agonist and antagonist by miR-430. Science. 2007:318:271-4.

68. Russart KL, Rhen T. Atrazien alters expression of reproductive and stress genes in the developing hypothalamus of the snapping turtle, Chelydra serpentina. Toxicology. 2016;366-367:1-9.

69. Murphy MB, et al. Atrazine concentrations, gonad gross morphology and histology in ranid frogs collected in Michigan agricultural areas. Aquat Toxicol. 2006:76(3-4):230-45.

70. McCoy KA, et al. Agriculture alters gonad form and function in the toad Bufo marinus. Environ Health Perspect. 2008;116(11):1526-32.

71. Tillitt DE, et al. Atrazine reduces reproduction in fathead minnow. Marine Environ Res. 2008;66(1):51-151.

72. Chi W, Tong CB, Gan XN, He SP. Characterization and comparative profiling of MiRNA transcriptomes in bighead carp and silver carp. PLoS One. 2011:6(8):e23549.

73. McBride D, Carre W, Sontakke SD, Hogg CO, Law A, Donadeu FX, Clinton M. Identification of miRNAs associated with the follicular-luteal transition in the ruminant ovary. Reproduction. 2012;144:221-33.

74. Christenson LK. MicroRNA control of ovarian function. Anim Reprod. 2010;7:129-33.

75. Fiedler SD, Carletti MZ, Hong $X$, Christenson LK. Hormonal regulation of MicroRNA expression in periovulatory mouse mural granulosa cells. Biol Reprod. 2008;79:1030-7.

76. Pan Q, Luo X, Toloubeydokhti T, Chegini N. The expression profile of micro-RNA in endometrium and endometriosis and the influence of ovarian steroids on their expression. Mol Hum Reprod. 2007:13:797-806.

77. Gangaraju VK, Lin HF. MicroRNAs: key regulators of stem cells. Nat Rev Mol Cell Bio. 2009:10(2):116-25.

78. Eshel O, Shirak A, Dor L, Band M, Zak T, Markovich-Gordon M, Chalifa-Caspi V, Feldmesser E, Weller Jl, Seroussi E, et al. Identification of male-specific amh duplication, sexually differentially expressed genes and microRNAs at early embryonic development of Nile tilapia (Oreochromis niloticus). BMC Genomics. 2014;15:774

79. Pasquinelli AE, Reinhart BJ, Slack F, Martindale MQ, Kuroda Ml, et al. Conservation of the sequence and temporal expression of let-7 heterochronic regulatory RNA. Nature. 2000;408:86-9.

80. Giraldez AJ, Cinalli RM, Glasner ME, Enright AJ, Thomson JM, Baskerville S, et al. MicroRNAs regulate brain morphogenesis in zebrafish. Science. 2005;308:833-8.

81. Giraldez AJ, Mishima Y, Rihel J, Grocock RJ, Van Dongen S, Inoue K, et al. Zebrafish MiR-430 promotes deadenylation and clearance of maternal mRNAs. Science. 2006:312:75-9.

82. Inui M, Martello G, Piccolo S. MicroRNA control of signal transduction. Nat Rev Mol Cell Biol. 2010;11:252-63.

83. Staton AA, Knaut H, Giraldez AJ. MiRNA regulation of Sdf1 chemokine signaling provides genetic robustness to germ cell migration. Nat Genet. 2011:43:204-11.

84. Li MWM, Mruk DD, Cheng CY. Mitogen-activated protein kinases in male reproductive function. Trends Mol Med. 2009;15:159-68.

85. Lau K, Lai KP, Bao JY, Zhang N, Tse A, Tong A, et al. Identification and expression profiling of microRNAs in the brain, liver and gonads of marine medaka (Oryzias melastigma) and in response to hypoxia. PLoS One. 2014;9:e110698. 
86. Hossain MM, Sohel MM, Schellander K, Tesfaye D. Characterization and importance of microRNAs in mammalian gonad functions. Cell Tissue Res. 2012;349:679-90.

87. Saunders LR, Sharma AD, Tawney J, Nakagawa M, Okita K, Yamanaka S, Willenbring $H$, Verdin E. miRNAs regulate SIRT1 expression during mouse embryonic stem cell differentiation and in adult mouse tissues. Aging-Us. 2010;2(7):415-31.

88. Sirotkin AV, Ovcharenko D, Grossmann R, Laukova M, Mlyncek M. Identification of microRNAs controlling human ovarian cell steroidogenesis via a genome-scale screen. J Cell Physiol. 2009;219(2):415-20.

89. Diego R, Laia R, Rosa C, Laura S, Francesc P, Paulino M, Ana V. Gene expression analysis at the onset of sex differentiation in turbot (Scophthalmus maximus). BMC Genomics. 2015;16:937.

90. Myosho T, Otake H, Masuyama H, et al. Tracing the emergence of a novel sex-determining gene in Medaka, Oryzias luzonensis. Genetics. 2012;191:163.

91. Moore A, Waring C. Mechanistic effects of a triazine pesticide on reproductive endocrine function in mature male Atlantic salmon (Salmo salar L.) parr. Pesticide Biochem Physiol. 1998;62:41-50.

92. Rey F, et al. Prenatal exposure to pesticides disrupts testicular histoarchitecture and alters testosterone levels in male Caiman latirostris. Gen Comp Endocrinol. 2009;162(3):286-92.

93. Friedmann A. Atrazine inhibition of testosterone production in rat males following peripubertal exposure. Reprod Toxicol. 2002;16(3):275-9.

94. Stoker $\mathrm{T}$, et al. The effect of atrazine on puberty in male Wistar rats: an evaluation in the protocol for the assessment of pubertal development and thyroid function. Toxicol Sci. 2000;58(1):50-9.

95. Wilhelms KW, et al. Effects of atrazine on sexual maturation in female Japanese quail induced by photostimulation or exogenous gonadotropin. Environ Toxicol Chem. 2006;25(1):233-40.

96. Caron-Beaudoin E, Denison MS, Sanderson JT. Effects of neonicotinoids on promoter-specific expression and activity of aromatase (CYP19) in human adrenocortical carcinoma (H295R) and primary umbilical vein endothelial (HUVEC) cells. Toxicol Sci. 2016;149:134-44.

97. Sanderson JT, Seinen W, Giesy JP, van den Berg M. 2-Chloro-s-triazine herbicides induce aromatase (CYP19) activity in H295R human adrenocortical carcinoma cells: a novel mechanism for estrogenicity? Toxicol Sci. 2000:54:121-7.

98. Sanderson JT, Letcher RJ, Heneweer M, Giesy JP, van den Berg M. Effects of chloro-s-triazine herbicides and metabolites on aromatase activity in various human cell lines and on vitellogenin production in male carp hepatocytes. Environ Health Perspect. 2001;109:1027-31.

99. Sanderson JT, Boerma J, Lansbergen GWA, van den Berg M. Induction and inhibition of aromatase (CYP19) activity by various classes of pesticides in H295R human adrenocortical carcinoma cells. Toxicol Appl Pharmacol. 2002;182:44-54.

100. Laville N, Bataguer P, Brion F, Hinfray N, Casellas C, Porcher J, Ait-Aissa S. Modulation of aromatase activity and mRNA by various selected pesticides in the human choriocarcinoma Jeg-3 cell line. Toxicology. 2006;228:98-108.

101. Pombinho AR, Laize V, Molha DM, Marques SM, Cancela ML. Cell Tissue Res. 2004:315:393-406.

102. Daniel MT. Et.al. Mir-20a regulates in vitro mineralization and BMP signaling pathway by targeting BMP-2 transcript in fish. Arch Biochem Biophys. 2014;543:23-30.

103. Pearson WR. Searching protein sequence libraries: comparison of the sensitivity and selectivity of the Smith-waterman and FASTA algorithms. Genomics. 1991;11:635-50.

104. Griffiths-Jones S. MiRBase: the microRNA sequence database. Methods Mo Biol. 2006;342:129-38.

105. Audic S, Claverie JM. The significance of digital gene expression profiles. Genome Res. 1997;7(10):986-95.

106. Kanehisa M, Araki M, Goto S, Hattori M, Hirakawa M, Itoh M, et al. KEGG for linking genomes to life and the environment. Nucleic Acids Res. 2008;36:D480-4.

\section{Publisher's Note}

Springer Nature remains neutral with regard to jurisdictional claims in published maps and institutional affiliations.

\section{Ready to submit your research? Choose BMC and benefit from:}

- fast, convenient online submission

- thorough peer review by experienced researchers in your field

- rapid publication on acceptance

- support for research data, including large and complex data types

- gold Open Access which fosters wider collaboration and increased citations

- maximum visibility for your research: over $100 \mathrm{M}$ website views per year

At BMC, research is always in progress.

Learn more biomedcentral.com/submissions 